\title{
Steady State ECRH for Next Step Superconducting Fusion Devices
}

\author{
V. Erckmann \\ Max-Planck-Institut für Plasmaphysik (IPP), EURATOM-Association, \\ D-17491 Greifswald, Germany
}

Information on the corresponding author:

Volker Erckmann

Max Planck Institut für Plasmaphysik,

Wendelsteinstrasse 1, D-17491 Greifswald, Germany

e-mail: volker.erckmann@ipp.mpg.de

Phone: +49-3834-88-2450 Fax: +49-3834-88-2459

Pages: $\quad 20 \quad$ (incl. Text, Ref., Tables, Figures and Fig. Captions)

Tables: $\quad 2$

Figures: $\quad 6$ 


\begin{abstract}
:
Controlled plasma start-up, heating towards thermonuclear fusion temperatures and steady state discharge control in advanced configurations is a major challenge for both, stellarators and tokamaks. Electron Cyclotron Resonance Heating (ECRH) and current drive (ECCD) plays a key role in the steady state operation scenarios of the ITER and JT-60 SA tokamaks as well as for the W7-X stellarator. The physics demands as well as the key technology of the different ECRH systems, which are similar in frequency and have continuous wave (cw) capability, is presented. Advanced solutions for future ECRH-systems are discussed.
\end{abstract}

Keywords: Nuclear Fusion, Electron Cyclotron Resonance Heating, Stellarator, Tokamak, Steady State Operation.

\title{
1. Introduction
}

The operation of the next step fusion devices is supported by powerful and flexible ECRH-systems [1]. EC-waves can be almost perfectly matched to the plasma and do not experience an evanescent layer as other rf-methods [e.g. 2, 3, 4]. The launching structure can therefore be placed far away from the plasma edge, which is of high importance for future devices operating at fusion relevant parameters and, some of them, with D-T mixtures. Shielding from nuclear radiation damage is less complicated and additional impurity problems, which arise from antenna-plasma interaction, are avoided. The next step fusion devices aiming at steady state operation are briefly introduced and characterized by their major parameters in Sec. 2. The ECRH-capability of plasma start-up from the neutral gas, control of plasma instabilities by ECCD, and performance optimization by plasma profile shaping assigns a key role to ECRH, some experiments are highlighted in Sec. 3.

The good theoretical understanding of the ECRH and ECCD physics and its experimental confirmation provides a safe basis for quantitative predictions. An ongoing refinement of theory allows for the treatment of the complex phase space physics of wave particle interaction in present day 3-D magnetic configurations, thus merging ECRH theory with the plasma transport [e.g. 5, 6], MHD-physics 
[e.g. 7, 8] as well as synergetic effects in combination with other rf-methods such as Lower Hybrid Current Drive (LHCD) [9].

The application of ECRH in next step large-scale devices requires sophisticated technological solutions as presented in Sec. 4. Strong R\&D efforts were undertaken in the EU, US, Japan and the Russian Federation within the last decade to develop MW-class cw gyrotrons in the desired frequency range of 110 to $170 \mathrm{GHz}$. Long distance, low loss transmission in continuous operation was developed. Waveguide solutions were favoured for ITER and JT 60SA, whereas a purely optical solution was chosen for W7-X. Some major parameters of the ECRH systems for the three large devices are listed in Table 1 together with the physics objectives. An outlook on advanced ECRH-components such as multi-frequency gyrotrons $[10,11]$ and fast directional switches (FADIS), which have a high potential to improve the present day baseline designs, is finally presented in Sec. 5 .

\section{Next step devices}

The ITER partners have launched national programs to investigate and explore steady state operation both, theoretically and experimentally. A necessary prerequisite for such investigations is a superconducting coil system, a steady state heating system as well as divertor structures for steady state heat removal and particle/impurity control. The next step devices as listed in Table 2 can be grouped in 'standard' D-shaped tokamaks, one compact spherical tokamak and one stellarator (note, that the Large Helical Device, LHD, is also a superconducting device of the stellarator type, which is in operation since a long time). They are designed to explore possible routes to steady state discharge scenarios and to address physics and technological questions arising during ITER construction and operation.

In tokamaks the inductively driven fraction of the total plasma current has to be replaced by externally (current drive) and internally (pressure-) driven currents with the desired radial current density distribution. Superconducting stellarators, on the other hand, have an inherent steady state operation capability, because the confining magnetic field is generated by external coils only. The absence of strong internal plasma currents reduces the reservoir of free energy in the plasma and eliminates the excitation of dangerous current driven MHD instabilities. Thus strongly localized 
ECCD for MHD-control is not an issue and the demands for ECRH application are reduced in comparison to ECRH for tokamaks. W7-X as well as the other listed next step devices (except NHTX) do not aim at DT-operation and provisions for remote handling, as necessary for ITER and its radioactive environment, are not foreseen.

NHTX is a representative of spherical tokamaks with a small aspect ratio and a low magnetic field. The compactness and the favorable surface to volume ratio make such devices attractive for the investigation of high power density plasma-wall interaction.

\section{Physics requirements for ECRH/ECCD systems}

\section{1 Plasma start-up}

Plasma start-up from the neutral gas is of particular importance for stellarators, because they rely on net-current free plasma generation and heating $[3,14]$. For large tokamaks, however, plasma start-up assist by ECRH becomes very attractive also, because the loop voltage for plasma break down must be limited and the saving of transformer flux as well as localized q-profile control during ramp-up is an important task. Plasma start-up assist thus became a common objective for all future ECRHsystems. An example is seen from Fig. 1, showing the start-up phase with ECRH preionization in the KSTAR tokamak [15], which recently went into operation. The break-down zone is clearly seen to be located near the resonance.

\subsection{Bulk-Heating and Current Drive}

Bulk heating and current drive is preferably performed with low field side launch in the equatorial plane (ITER and W7-X) or from upper outboard ports (JT 60 SA). The standard heating and current drive scenario is $1^{\text {st }}$ harmonic O-mode $(\mathrm{O} 1)$ for ITER and $2^{\text {nd }}$ harmonic extraordinary mode $(\mathrm{X} 2)$ for most of the next step devices with lower magnetic field, except for JT-60 SA with 110 and $140 \mathrm{GHz}$, where the lower frequency can be applied also in $1^{\text {st }}$ harmonic. The two-frequency ECRH for W7-X allows operation at $1.25 \mathrm{~T}(\mathrm{X} 3)$ and $1.87 \mathrm{~T}(\mathrm{X} 2, \mathrm{O} 2)$ with $104 \mathrm{GHz}$, as well as $1.66 \mathrm{~T}(\mathrm{X} 3)$ and $2.5 \mathrm{~T}$ (X2, O2) with $140 \mathrm{GHz}$, respectively [16]. High-density operation above the X2 cut-off is favorable for efficient divertor action and the related physics studies on particle and impurity control. This den- 
sity regime is accessible with the $\mathrm{O} 2$ mode, which has a cut-off density of $\mathrm{n}_{\mathrm{e}}<2.5 \cdot 10^{20} \mathrm{~m}^{-3}[17]$ and with O-X-Bernstein-wave (OXB) mode conversion heating [18] at even higher density. O2-mode heating has an incomplete single pass absorption at the W7-X plasma parameters and the wave beam is thus guided for well defined double pass absorption by in-vessel mirrors at the high field side. Theoretical investigations show, that $\mathrm{X} 3$-heating $\left(\mathrm{B}_{\mathrm{res}}=1.66 \mathrm{~T}, \mathrm{n}_{\mathrm{e}}<1.6 .10^{20} \mathrm{~m}^{-3}\right)$ is an interesting scenario for operation at reduced magnetic field in W7-X, too [6]. As W7-X has no OH-transformer for inductive current drive, EC-current drive is a valuable tool to modify the internal current density distribution and to counteract small residual bootstrap currents [5], which are zero only in a narrow parameter range.

Electron Bernstein Wave (EBW) heating is the only applicable scenario in the EC-range of frequencies for spherical tokamaks, because $\omega_{\mathrm{pe}}>>\omega_{\mathrm{ce}}$ for the low magnetic field, where $\omega_{\mathrm{pe}}$ and $\omega_{\mathrm{ce}}$ are the plasma and the electron cyclotron frequency, respectively [19]. Standard, low harmonic electromagnetic modes cannot penetrate the core of such overdense plasmas, whereas EBWs do not suffer from any upper density limit and have a high absorption near the cyclotron harmonics. For stellarators, which have no density limit such as the Greenwald limit in tokamaks, operation at very high densities is an attractive regime also [20] and is only accessible with EBW-heating. EB-waves can be excited by the OXB-conversion process or direct X-B conversion [18].

\subsection{MHD-mode stabilization}

Stabilization of MHD-modes by localized CD in the O-point of the magnetic island or prevention of MHD-activity by localized current drive at the resonant flux surface is a major task devoted to ECRH in tokamaks [7, 21]. MHD-modes become unstable at resonant flux- surfaces with low order rational numbers of q, which means, that stabilization of these modes requires an accurate knowledge (within centimeters) of the radial location of the instability. Narrow RF-beams then have to be steered to this position with high accuracy, which, at the same time must satisfy the EC-resonance condition. As different MHD-modes such as the 2/1 and the 3/2 neoclassical tearing modes (NTM), sawteeth (at q=1) as well as Edge Localized Modes (ELMs) may need to be mitigated or suppressed, it follows, that the steering range of the ECRH-beams must cover most of the plasma cross section. 
The MHD-mode stabilization is most efficient, once the power driving the localized current is deposited completely within the island, whereas power deposited in the vicinity of the X-point outside the island destabilizes the mode [22]. Thus the island width and rotation frequency determines the optimum power deposition width and power modulation frequency, respectively. A power deposition width of about $20 \mathrm{~mm}$ was measured in NTM-stabilization experiments at AUG [23] and DIII-D [24], which is sufficient for efficient current drive in the O-point of the island by modulated ECRH. The topology for the 2/1 NTM mode suppression experiments in DIII-D [24] is sketched in Fig. 2 (a), the power deposition width is seen in the blown up insert in Fig. 2 (b). Sophisticated integrated schemes for the detection of NTMs, identification of their location, localized current drive at the island position, and synchronization of the power modulation to the island rotation frequency were developed in different tokamaks [e.g. 23, 25, 26]. An example from DIII-D is seen from Fig. 2 (c), where the island width of a 2/1 NTM is reduced from about $60 \mathrm{~mm}$ down to the detection limit within typically $400 \mathrm{~ms}$ by feedback controlled localized ECCD. In the control algorithm of the various experiments both the resonance position, i.e. the magnetic field, or the position of the $\mathrm{q}=2$ resonant surface, i.e. the plasma position were adjusted to match the ECRH-deposition. The measured radial position of the island and the radial position of the EC-power deposition (both expressed in the major radius coordinate R) are also plotted showing the achieved accuracy. The experiments were extended towards prevention of the mode destabilization by local current drive at the respective resonant layer [27]. Tuning the magnetic field to shift the EC-power deposition to the island location may, however, not work in superconducting devices. In this case a more appropriate approach for real-time feedback stabilization by steering the EC-wave beams towards the island location was successfully performed at JT-60U [37].

\subsection{Steady state operation}

Stationary operation of tokamaks is obtained only, if the inductively driven current component is replaced by external CD-methods in continuous operation. The available experimental data base is small, which assigns a key role to the next generation devices in exploring the cw-regime at high density and fusion relevant temperatures. Off-axis current drive is required for advanced tokamak 
scenarios with flat or inverse q-profiles and LHCD has the highest CD-efficiency in off-axis deposition. Interesting experiments on synergetic effects with combination of ECRH and LHH were performed at TORE SUPRA [9] in quasi steady state operation. The discharge was maintained for $30 \mathrm{~s}$ with an incident $\mathrm{LH}$ power of $3 \mathrm{MW}$ in combination with an ECRH power of $0.7 \mathrm{MW}$ for $10 \mathrm{~s}$ at a density of $1.810^{19} \mathrm{~m}^{-3}$ and central electron and ion temperatures of $6-8 \mathrm{keV}$ and $1.7 \mathrm{keV}$, respectively. A well localized current with enhanced current drive efficiency was measured, which is explained by phase space interaction of the EC-wave and LH-wave coupling.

The demands for steady state operation of stellarators are relaxed in comparison to tokamaks, as current drive is a control tool to balance small internal pressure driven currents rather than a tool for the replacement of large inductive currents [29]. Furthermore, the stabilization of current driven MHD-modes is not an issue. Experiments at LHD have demonstrated stationary operation for $3900 \mathrm{~s}$ with $110 \mathrm{~kW}$ ECRH power at $84 \mathrm{GHz}$. Due to the low available input power in cw-mode, the density had to be kept as low as $1.510{ }^{18} \mathrm{~m}^{-3}$ with a central electron temperature exceeding $1 \mathrm{keV}$ [30].

Steady state scenarios for W7-X with ECRH only were investigated theoretically. Such operation scenarios must comply with an efficient divertor operation for stationary heat removal and particle control, which is restricted to high densities. The studies therefore concentrate on the development of O2-mode scenarios. An example for the plasma build-up to high densities is shown in Fig. 3, where the time traces of some plasma parameters for the $10 \mathrm{MW} \mathrm{O2-mode} \mathrm{scenario} \mathrm{are} \mathrm{shown} \mathrm{[6].}$ Initially the $0.6 \times 10^{20} \mathrm{~m}^{-3}$ plasma is heated by $5 \mathrm{MW}$ X2-mode and then taken over with O2-mode. The simulation is continued by ramping-up the density to $2 \times 10^{20} \mathrm{~m}^{-3}$ with an increased heating power of $10 \mathrm{MW}$ thus avoiding a thermal instability due to the $\mathrm{T}_{\mathrm{e}}^{2}$ dependence of the O-mode absorption. The final temperatures and power deposition profiles are shown in Fig. 3 (d) and (e), respectively.

\section{ECRH-Technology}

\subsection{Gyrotrons}

High power gyrotrons are the backbone of large-scale ECRH systems. The state of the art of high power gyrotron development is presented in the review paper [31] and the references therein. Strong 
$R \& D$ efforts were launched in the past decade driven by the needs of ITER and W7-X. Gyrotrons with typically $1 \mathrm{MW}$ output power in cw-mode with an efficiency of $35-55 \%$ were developed in Japan with Toshiba [32], EU with THALES [33, 34], USA with CPI [35] and the Russian Federation with GYCOM [36] as industrial partners, respectively. Note, that the ITER sources at $170 \mathrm{GHz}$ are to be supplied by Russia, Japan and EU, each of them contributing with 8 MW. Besides the ITER development, Japan/Toshiba has extended its R\&D program to $110 \mathrm{GHz}$ for JT-60 SA, Russia/GYCOM develops also the two- and multi-frequency gyrotrons for AUG, EU/THALES has successfully developed the W7-X gyrotron at $140 \mathrm{GHz}$, US/CPI is working on $110 \mathrm{GHz}$ for DIII-D and has successfully completed the $140 \mathrm{GHz}$ R\&D for W7-X. An rf-power in the directed beam of 0.9 MW (CPI) and 0.92 MW (THALES) were obtained for 30 min operation, both gyrotrons met the W7-X specifications. Also the ITER specifications (1 MW rf-output for $500 \mathrm{~s}$ ) were fully met recently by Japan/Toshiba. Whereas the ITER gyrotrons developed in Russia, US and Japan are based on cylindrical cavity modes with $1 \mathrm{MW}$ power as the target, the EU development aims at $2 \mathrm{MW}$ output power with a coaxial cavity gyrotron.

\subsection{High-power Microwave Transmission}

With the increasing size of the ECRH-systems for next step devices, the gyrotrons have to be installed in a separate hall rather than in the neighbourhood of the fusion device. The ITER arrangement is shown in Fig. 4, were the rf-power is transmitted by separate waveguides towards the ITER ports over a typical distance of 50 to $80 \mathrm{~m}$. Evacuated corrugated waveguides for low-loss HE11-mode transmission are used at ITER, which are designed to satisfy the safety requirements with respect to the Tritium containment. The transmission system for JT-60SA and for the other next step devices are also waveguide based with some individual choice of the waveguide dimensions. A major issue for long distance waveguide transmission is the conservation of the low loss HE11 mode, where the mitre bends are the most critical components, because they are symmetry breaking elements generating wrong modes. For ITER, $20 \mathrm{MW}$ port through power is specified, the installed power is $24 \mathrm{MW}$ assuming total transmission losses of $17 \%$. It is worth noting, that no further coupling losses from antenna to plasma have to be considered as it is the case for other rf-methods. 
For $\mathrm{W} 7-\mathrm{X}$ a purely optical transmission system was realized. The arrangement of the 10 gyrotrons (1 MW, cw each), auxiliary systems, and transmission line is sketched in Fig. 5 [38]. The modular structure is seen from the photographs. The transmission of the rf-power to the torus over a distance of typically $60 \mathrm{~m}$ is performed by two open multi-beam waveguide (MBWG) mirror lines, each of them combining and handling 5 individual rf-beams. The beam conditioning near the gyrotrons and the beam distribution near the torus ports are performed by single-beam waveguide (SBWG) sections, respectively. An underground concrete duct houses the individual components of the transmission system. The concrete walls are an efficient absorber of stray radiation from the open lines. All mirrors in the beam duct are remotely controlled.

High-power, cw tests of the entire transmission line can only be performed once the W7-X construction is completed and access to the main torus hall is provided. We have therefore installed retro-reflectors to test the full distance transmission by transmitting the high power beams half way in forward direction and then back via the reflectors to the dummy load. Total losses of $2.6 \pm 0.4 \%$ were measured for 10 reflections over a total length of about $40 \mathrm{~m}$, which is close to the theoretical minimum losses of $2.7 \%$ [39].

\subsection{Launchers}

Due to the absence of an evanescent layer, the EC-wave beams can be launched from remote antennas via a set of steerable mirrors with imaging characteristics. This so called 'front steering launcher' (FSL) concept is widely used, because it provides a high flexibility in connection with high accuracy. Two types of FSLs are foreseen for ITER: The equatorial port launcher is designed for bulk heating, on/off axis steady state current drive, and start-up assist [40]. Altogether 24 waveguides transmitting a total power of $20 \mathrm{MW}$ are stacked at one port, the steering range of the mirrors is 20 to $45 \mathrm{deg}$ in toroidal direction to optimize power deposition and current drive. A set of dedicated FSLs in four upper ports is foreseen for NTM stabilization [41].

For W7-X altogether 10 rf-beams (plus two spare) will be launched through 4 equatorial ports for the Low Field Side-launch scenarios [16]. The wide steering range complies with all heating and 
CD scenarios including O-X-B heating. Two out of the ten beam lines can be switched towards two special ports for the High Field Side (HFS) scenarios.

\section{Advanced technology concepts}

\subsection{Multi frequency gyrotrons}

Gyrotrons operating at two or more frequencies would increase the flexibility of ECRH-systems and simplify the launchers, because the power deposition can be controlled at a given magnetic field by tuning the frequency. A simplified and robust launcher, which ideally has no moving parts, may be particularly advantageous for reactor like devices with long self sustained burn phases, because of its high reliability in a hostile environment, simplified remote maintenance and replacement. Two types of multi-frequency gyrotrons can be distinguished: Two or three-frequency operation is possible with the conventional design making use of the resonant nature of the diamond window, which is transparent for multiples of $\lambda / 2$ ( $\lambda$ is the rf-wavelength in the diamond). Both, the THALES gyrotrons for W7-X and the GYCOM gyrotrons for AUG operate at 140 and $105 \mathrm{GHz}$. The latter have demonstrated e.g. $0.73 \mathrm{MW}$ at $105 \mathrm{GHz}$ and $0.94 \mathrm{MW}$ at $140 \mathrm{GHz}$, respectively, in 10 s pulses [42]. An ITER gyrotron would work at $170 \mathrm{GHz}$ and $136 \mathrm{GHz}$, once designed for two frequency operation.

A second type of gyrotrons, which makes use of the dense spectrum of high order cavity modes, can operate at many frequencies $[43,44]$. Such step tunable gyrotrons need a broad band Brewster-type window, which is investigated by IAP Nizhny Novgorod in the frame of the R\&D on multi-frequency gyrotrons for AUG. Experiments are expected soon [11].

\subsection{Fast Directional Switches (FADIS)/Beam combiners}

High power microwave transmission systems need switches, e.g. for switching from the laucher to the dummy load, or, in case of ITER, for switching from the equatorial launcher to the upper launcher. The design of such switches is based on movable mirrors in open systems or integrated in mitre-bends. Such switches are slow, because mechanical elements have to be moved, and have an undefined state during switching with the consequence, that the gyrotron emission has to be turned off during the switching process. 
A FADIS, on the other hand, can switch an input microwave beam between two output channels without moving parts and is thus very fast. The switching is controlled by a small frequencyshift keying of the gyrotron of about a few ten's of MHz between $f_{1}$ and $f_{2}$. Such devices are known in electronics as diplexers. Switching can always be performed with the source operating continuously, because the diplexer behaves like a logical element with no undefined state: the input power is always in output one or in output two, or in both. An interesting application is MHD stabilization: As the islands rotate with frequencies of typically 1 to $10 \mathrm{kHz}$, injection of the launched power synchronous with the rotating islands is required. This is performed up to now by on/off power modulation of the gyrotron, which means, that half of the installed power is wasted. Synchronous toggling of the gyrotron power by a FADIS between two plasma positions, which are about $180^{\circ}$ apart from each other with respect to the phase of the NTM would make full use of the available power, i.e. double the efficiency. Alternatively, the power of one output can be used for synchronous NTM stabilization, while the other output feeds the midplane launcher for an independent ECRH or ECCD experiment.

A principal sketch of a diplexer is shown in Fig. 6 (left). As any diplexer can be designed as four-port device, two gyrotrons can be fed into it [45]. If both gyrotrons are shifted between frequen$\operatorname{cies} f_{1}$ and $f_{2}$, but in opposite phase ("push-pull"), then the power of both gyrotrons is combined into one of the two outputs [46], which is then switched between output 1 and 2. High-power diplexers can be based on varios concepts and integrated in quasi-optical as well as waveguide based transmission lines. First high power experiments combining the input power of $0.37 \mathrm{MW}$ at input 1 and $0.56 \mathrm{MW}$ at input 2 and switching of the combined $0.93 \mathrm{MW}$ beam with up to $20 \mathrm{kHz}$ were performed successfully with a quasi-optical (QUO-) FADIS prototype [47] based on the concept as sketched in Fig. 6 (right). The results strongly motivate the development of power combiners and fast switches until maturity. The application of a FADIS in ECRH experiments at AUG and FTU are planned [48]. A future doubling of the ECRH-power for ITER can for example be realized without doubling of the number of transmission lines between the switch and the launchers. Toggling of the combined beam between the equatorial port and the upper ports during a discharge would be possible with the same arrangement also. 


\section{Summary and conclusions}

ECRH is a multi-purpose day-one system for the large next step superconducting devices ITER, W7$\mathrm{X}$ and JT-60 SA to support steady state operation. Very flexible ECRH-systems are required to meet the different tasks such as plasma start-up, configuration control by bulk heating and current drive, and MHD-control and/or MHD-prevention by localized current drive. A rich experimental data-base exists from many present day fusion devices providing a viable basis even for sophisticated ITERcompatible feed-back control scenarios. On the other hand, the experimental basis for steady state operation is very limited and the exploration of integrated $\mathrm{cw}$ operation scenarios thus remains with the next step devices. The physics of the EC-wave particle interaction is well understood and sophisticated theoretical tools for quantitative predictions are available. The technology of ECRH has made significant progress in the past decade, with dedicated R\&D being driven by the needs of ITER and W7-X. The $10 \mathrm{MW}$, cw ECRH-plant for W7-X is close to completion and integrated tests have established a high confidence in large scale, cw ECRH-systems. Prototype industrial cw gyrotrons with the specified power in the desired frequency range became available for both, W7-X and ITER. Series production of reliable and robust units may, however, need additional attention. Both options of the $\mathrm{cw}$ transmission technology, the waveguide based and the mirror based optical transmission was developed towards maturity. The optical multi-megawatt transmission line for $\mathrm{W} 7-\mathrm{X}$ has proven to be a viable option with very low losses close to the theoretical minimum losses and high power, cw operation was demonstrated. The waveguide based transmission line, which is the preferred solution for the other devices, is well developed with some potential to reduce the transmission losses further. The optimum launching structure, which meets the requirements for wide angle beam steering and narrow power deposition at the same time, is the two-mirror front steering concept, which is now used in practically all devices.

New developments are under way, which have the capability to improve present day ECRHbaseline designs significantly: Two-frequency and/or multi-frequency gyrotrons can increase the flexibility further and have reached already an impressive performance. 
The recent development of four-port diplexers as high-power fast directional switches (FADIS) and rf-beam combiners offers new perspectives for power handling and distribution, e.g. for switching of the rf-beams between different launchers during a discharge or for power upgrade of an ECRH system without increasing the number of transmission lines, thus saving also port space. FADIS would also allow to combine rf-diagnostics, say ECE, and heating while sharing one common launcher channel with the advantage of having the same line of sight and saving port space.

\section{Acknowledgement}

The valuable discussions and contributions from many colleagues at different fusion laboratories are gratefully acknowledged. 


\section{References}

[1] H. Zohm : Fusion Science and Technolgy, Vol 52 (2007) 134-144

[2] M. Bornatici, R. Cano, O. De Barbieri, F. Englemann, Nucl. Fusion 23, 1159 (1983).

[3] V. Erckmann, U. Gasparino, Plasma Phys. Conrol. Fusion 36, 1869(1994).

[4] R. Prater: Heating and current drive by electron cyclotron waves, Phys. Plasmas 11 (2004) 2349

[5] Marushchenko, N. B., V. Erckmann, H.P. Laqua, H. Maassberg and Y. Turkin: 34th EPS Conference on Plasma Phys. Warsaw (2007) ECA Vol.31F, P-5.129 (2007)

[6] Turkin, Y., C. D. Beidler, A. Dinklage, J. Geiger, et al.: 33rd EPS Conference on Plasma Phys., Rome (2006) ECA Vol.30I, P-2.113 (2006)

[7] H. Zohm, Phys. Plasmas, 4 (1997) 3433

[8] G. Giruzzi et al., Nucl. Fusion 39 (1999) 107

[9] G. Giruzzi, J.F. Artaud, R. J. Dumont, F. Imbeaux, et al.: Phys Rev. Letters 93, 255002 (2004)

[10] G. G. Denisov, A.G. Litvak, V.E. Myasnikov, E.-M. Tai, V.I. Illin, V. E. Zapevalov, Proc. Strong Microwaves in Plasmas, Nizhny Novgorod, Russia, Vol 1 (2006) 62-75

[11] D. Wagner, F. Leuterer, A. Manini, F. Monaco, et al. Fusion Science and Technolgy, Vol 52 (2007) 313-320

[12] M. Shimada et al., Nucl. Fusion 47 (2007) S1-S17

[13] Y.S. Bae, Y.S. Na, Y.K. Oh, M. Kwon, et al. Fusion Science and Technology Vol 52 (2007) 321-333

[14] V. Erckmann, H.P. Laqua, H. Maaßberg, et al.: Nucl. Fusion 43 (2003) 1313-1323

[15] Y.S. Bae, privat communication

[16] V. Erckmann, P. Brand, H. Braune, G. Dammertz, et al., Fusion Science and Technology, Vol. 52, No.2 (2007) pp. 291-312

[17] M. Rome', V. Erckmann, U. Gasparino, N. Karulin, Plasma Phys. Control. Fusion 40 (1998) 511-530

[18] H.P. Laqua: Plasma Phys. Control. Fusion 49, No 4 (2007) R1-R42

[19] V. Shevchenko, G. Cunningham, A. Gurchenko, E. Gusakov, et al.: Fusion Science and Technoloogy, Vol. 52 (2007) 202-215

[20] K. McCormick, P. Grigull, R. Burhenn, R. Brakel, et al.: Phys. Rev. Letters 89 (2002) 1131

[21] R.J. La Haye, AIP Conf. Proc.Vol 933: Radio Frequency Power in Plasmas, Florida, USA, ISBN 978-0-7354-0444-1, ISSN 0094-243X, (2007) 361-368

[22] H. Zohm, G. Gantenbein, G. Giruzzi, et al. Nucl. Fusion 39, No 5 (1999) 577-580

[23] F. Leuterer, R. Dux, G. Gantenbein, J. Hobirk, et al.: Nucl. Fusion 43 (2003) 1329-1342

[24] D.A. Humphreys, J.R. Ferron, M. Bakhtiari, et al.: Nucl. Fusion 47 No 8 (2007) 943-951

[25] T.C. Luce et al. J. Phys.: Conf. Ser. 25 (2005) 252-256

[26] G. Gantenbein, H. Zohm, G. Giruzzi, S. Günter, et al.: Phys. Rev. Lett. 85 (2000) 1242

[27] R. Prater, R.J. La Haye, T.C. Luce, C.C. Petty, et al.: Nucl. Fusion 47 No 5 (2007) 371-377

[28] A. Isayama, Y. Kamada, N. Hayashi, et al. : Nucl. Fusion 43 (2003) 1272-1278

[29] Turkin, Y., H. Maßßberg, C.D. Beidler, J. Geiger and N. B. Marushchenko: Fusion Science and Technology 50 (2006) 387.

[30] Y Yoshimura, S Kubo, T Shimozuma, H Igami, et al.: Journal of Physics, Conf. Series 25 (2005) 189-197

[31] K. Sakamoto: Fusion Science and Technology, Vol. 52 (2007) 145-153

[32] K. Sakamoto, A. Kasugai, K. Takahashi, et al. Nature physics, Vol 3, June 2007

[33] G. Dammertz, S. Alberti, A. Arnold, E. Borie, et al., IEEE Trans. Plasma Science 30 (2002) 808-818

[34] B. Piosczyk, et al. IEEE Trans. Plasma Sci. 32 (2004) 413

[35] K. Felch, M. Blank, P. Borchard, P. Cahalan, et al. Journal of Physics: Conference Series 25 (2005) pp. 13-23.

[36] A. Litvak: Proc. 21st Fusion Energy Conf., Chengdu, China, (2006) IAEA

[37] C. Darbos, privat communication 
[38] W. Kasparek, P. Brand, H. Braune, G. Dammertz, et al., Fusion Engineering and Design 74 (2005) 243-248

[39] V. Erckmann1, W. Kasparek, G. Gantenbein, F. Hollmann, et al. acc. for publ. in Fusion Science and Technology

[40] K. Takahashi, N. Kobayashi, J. Ohmori, S. Suzuki, A. Kasugai, K. Sakamoto, Fusion Science and Technolgy Vol 52 (2007) 266

[41] M. A. Henderson et al.: J. Phys. Conf. Ser., 25 (2005) 143

[42] V.O. Nishiporenko et al.: Proc. 31st Conf. IRMMW/14 ${ }^{\text {th }}$ Int. Conf. Terahertz electronics, Shanghai, China (2006) 172

[43] M. Thumm et al.: Fusion Engineering and Desing, 53 (2001) 407

[44] G.G. Denisov, A.G. Litvak, V.E. Myasnikov, et al.: Nucl. Fusion 48 (2008) 054007

[45] M.I. Petelin, et al, in: High Energy Density Microwaves, ed. by R.M. Phillips, AIP Conference Proc. 474 (1998), 304 - 315.

[46] W. Kasparek, M. Petelin, V. Erckmann, D. Shchegolkov, et al.: Fusion Sci. Technol. 52 (2007), $281-290$

[47] V. Erckmann, W. Kasparek, Y. Koshurinov, L. Lubyako, et al.: acc. for publ. in Fusion Science and Technology

[48] W. Kasparek, M. Petelin, V. Erckmann, A. Bruschi, F. Noke, et al.: acc. for publ. in Fusion Science and Technology 


\section{Figure Captions}

Figure 1 : Plasma start-up assist with ECRH pre-ionization in KSTAR with $0.5 \mathrm{MW}$ at $84 \mathrm{GHz}$. The $2^{\text {nd }}$ harmonic resonance with $\mathrm{B}_{\mathrm{t}}=1.5 \mathrm{~T}$ is indicated (dashed line) as well as the plasma axis (solid line) [15].

Figure 2: NTM-stabilization experiments at DIII-D with $2^{\text {nd }}$ harmonic X-mode launch [24]: (a) 2/1 mode island geometry, (b) expanded region of power deposition, (c) time traces of the ECRH power $\mathrm{P}_{\text {ech }}$, NTM island width, radii of the EC-power deposition $\mathrm{R}_{\mathrm{ec}}$ and the position of the $\mathrm{q}=2$ surface, $\mathrm{R}_{\mathrm{qin}}$, respectively.

Figure 3: Simulation of the plasma development towards high density steady state parameters in W7-X [6]: (a) initial electron $\left(\mathrm{T}_{\mathrm{e}}\right)$ and ion $\left(\mathrm{T}_{\mathrm{i}}\right)$ temperature profiles; (b) power deposition profile in X2-mode; (c) time evolution of the central temperatures $T_{e}$ and $T_{i}$, triple product $n_{i} T_{i} \tau_{E}$ in $10{ }^{20} \mathrm{~m}^{-3}$ $\mathrm{keV} \mathrm{s}$, central density $\mathrm{n}_{\mathrm{e}}$, energy confinement time $\tau_{\mathrm{E}}$, and the the maximum value of the central radial electric field $E_{\mathrm{r}}$ in $\mathrm{kV} / \mathrm{m}$; (d) final temperature profiles and (e) ECRH power deposition profile in O2-mode.

Figure 4: The ITER ECRH-plant [37|. The gyrotron hall is seen on the left, the arrangement of 24 gyrotrons occupies the left half of the hall with spare space for a doubling of the power. The transmission lines connect the gyrotrons to the equatorial port (24 waveguides) and/or the 4 upper ports for MHD stabilization.

Figure 5: The ECRH-plant for W7-X: Left: sketch of the gyrotron and transmission line arrangement in the ECRH-building, cross section (a) and top view (b). Right: Modular arrangement of Gyrotron and cooling units (top). HV-installation at ground-floor (bottom).

Figure 6: left: Principle sketch of a four-port diplexer. Power combination of two gyrotron $\mathrm{G}_{\mathrm{A}}$ and $G_{B}$ with frequency $f_{2}$ and $f_{1}$, respectively (solid arrows only) and switching of the combined beam (solid/dashed arrows). right: Sketch of a quasi-optical FADIS (QUO-FADIS) using a 4-mirror quasioptical ring-resonator with grating couplers. Only one input-port (grating coupler) is used. The incident beam is emitted through output 'Out 1' or 'Out 2' depending on the frequency. 


\section{Figure 1:}

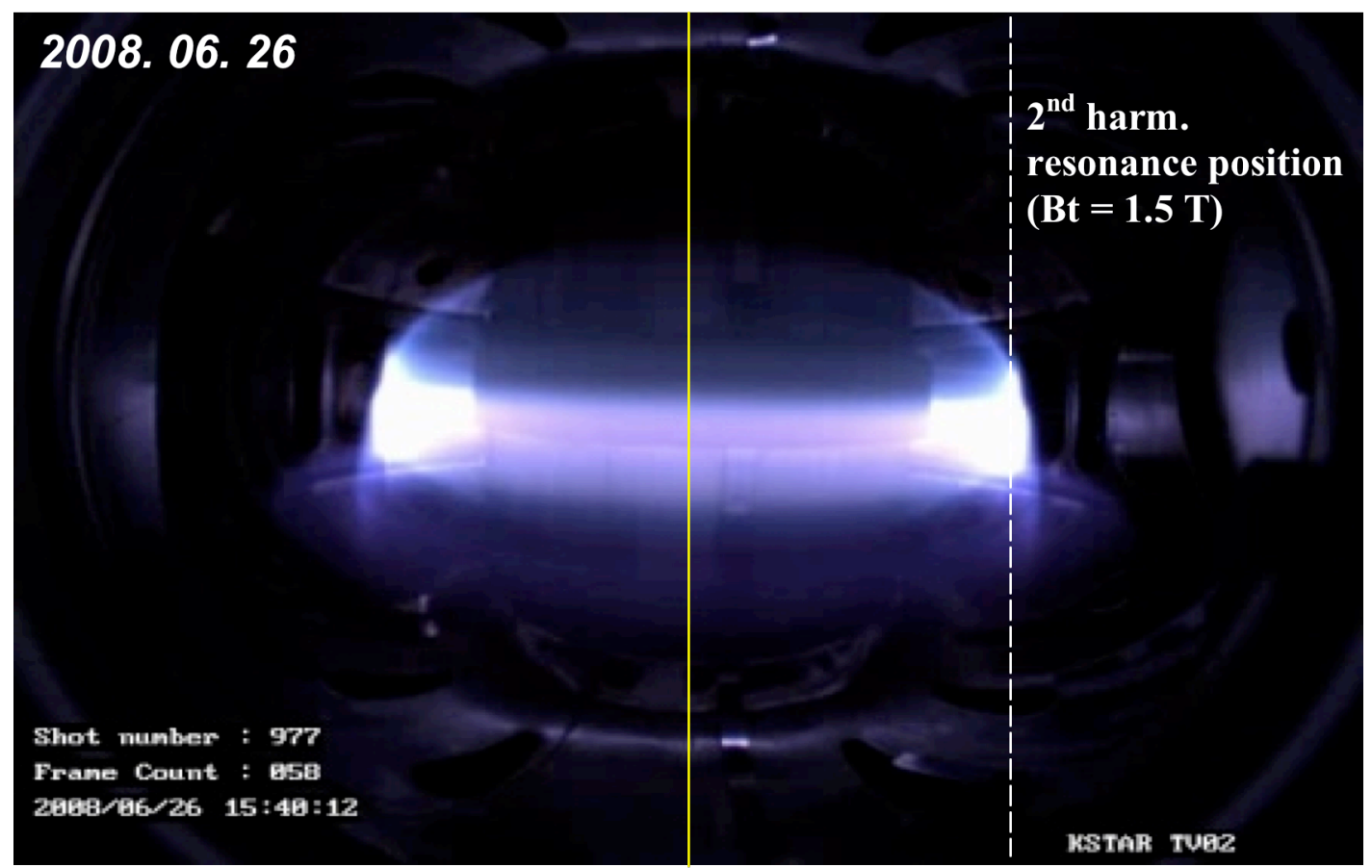

Figure 2:

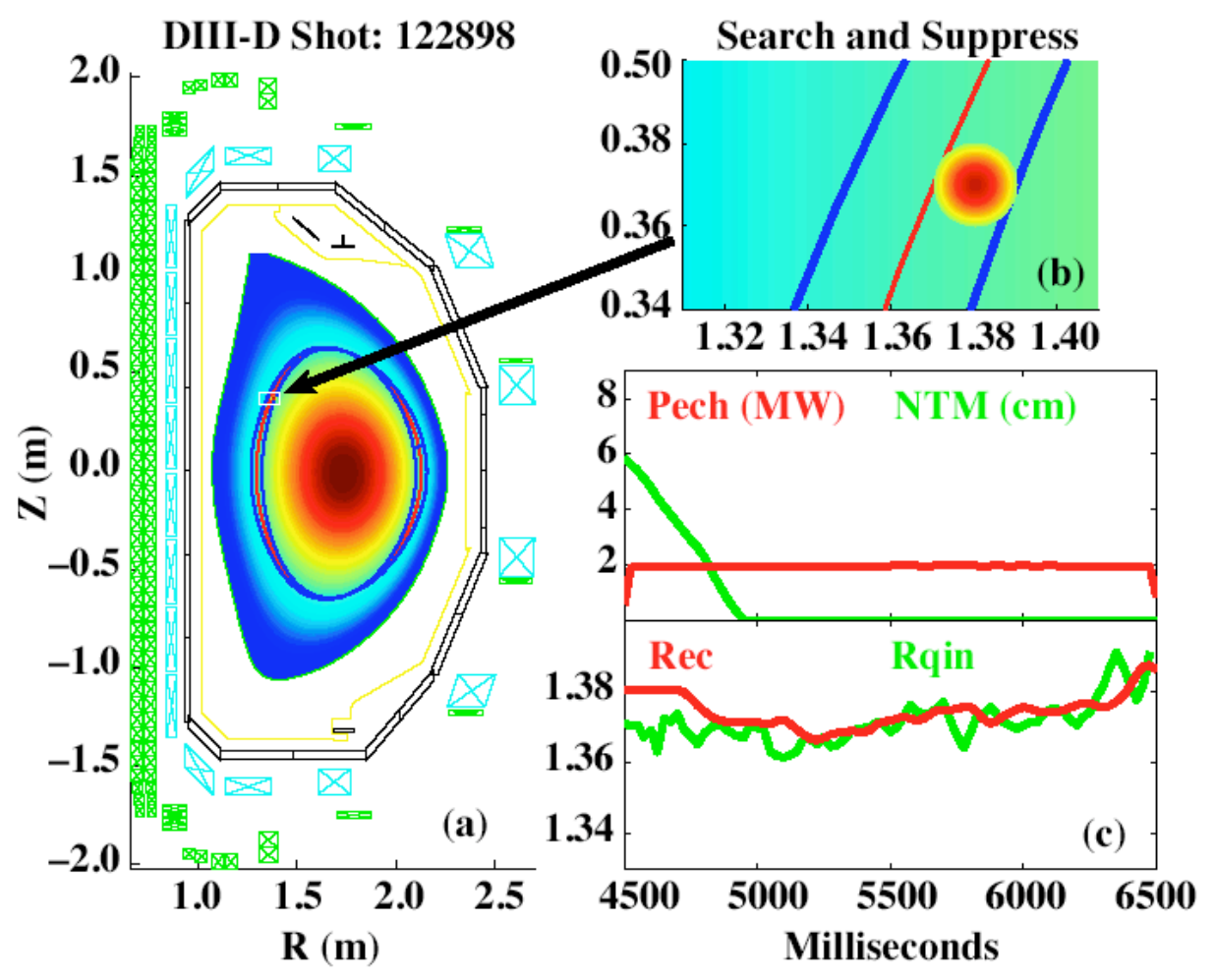


Figure 3:
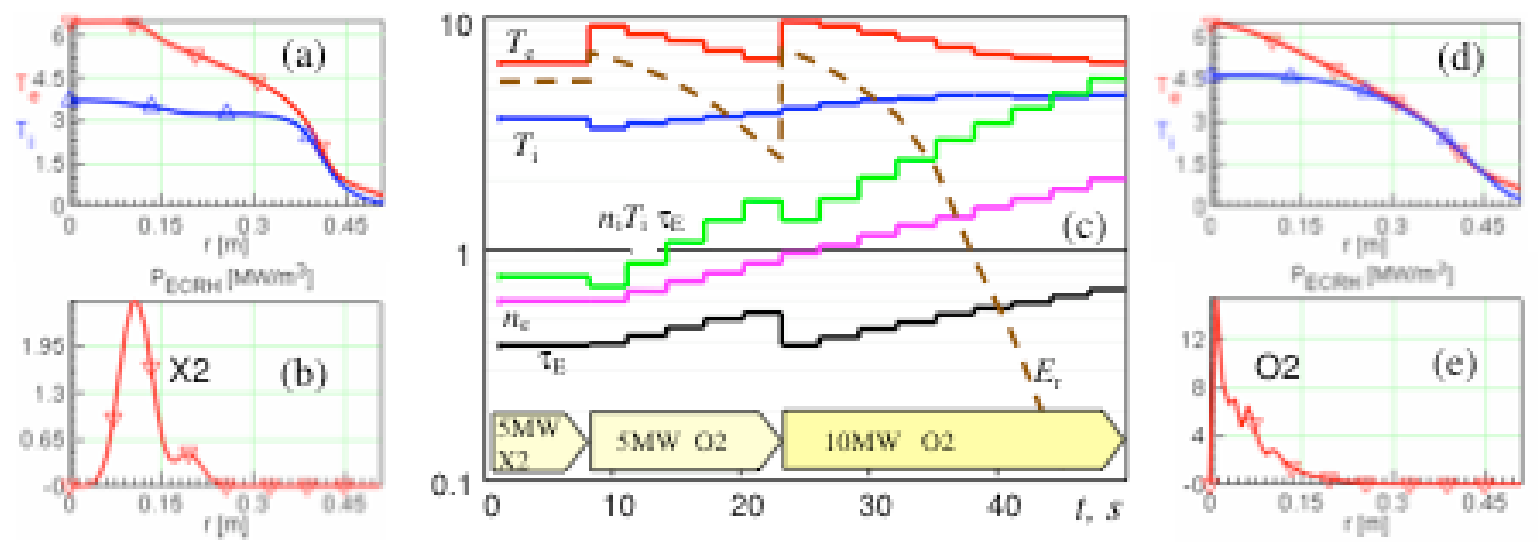

Figure 4:

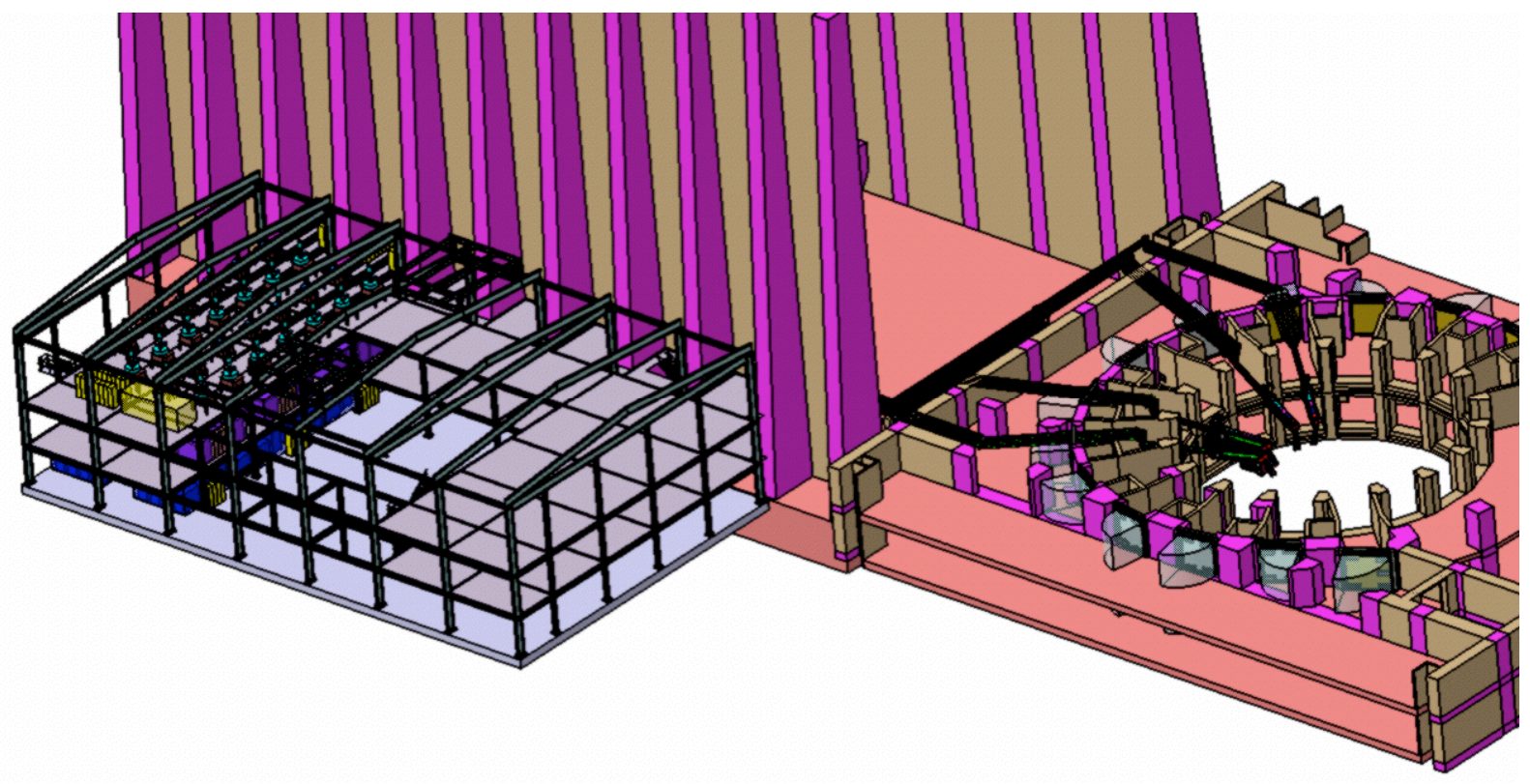


Figure 5:

a)

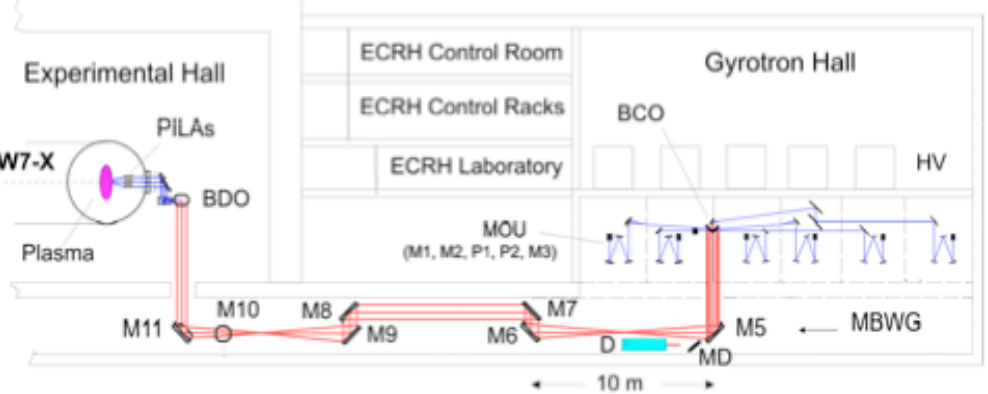

b)
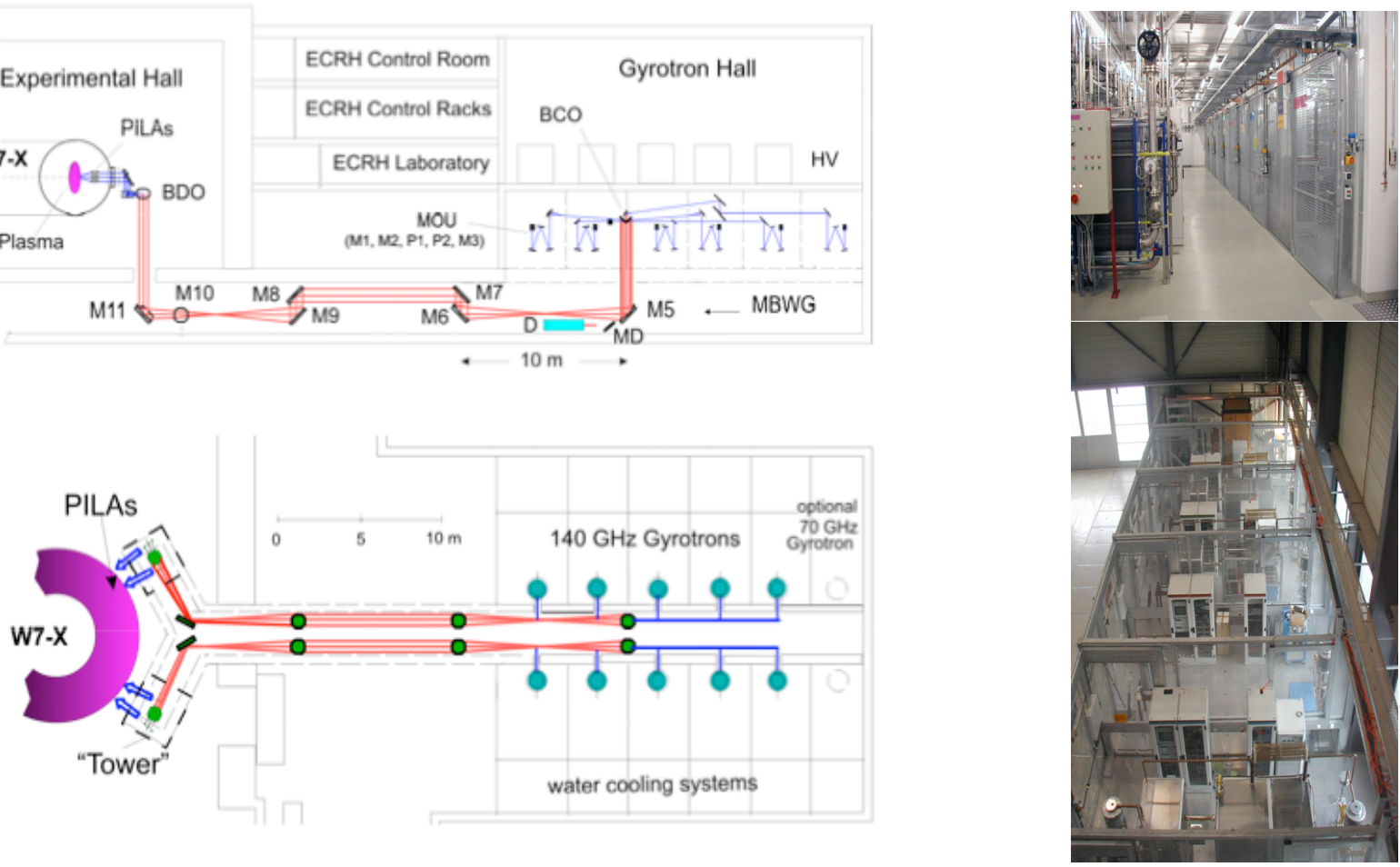

Figure 6:
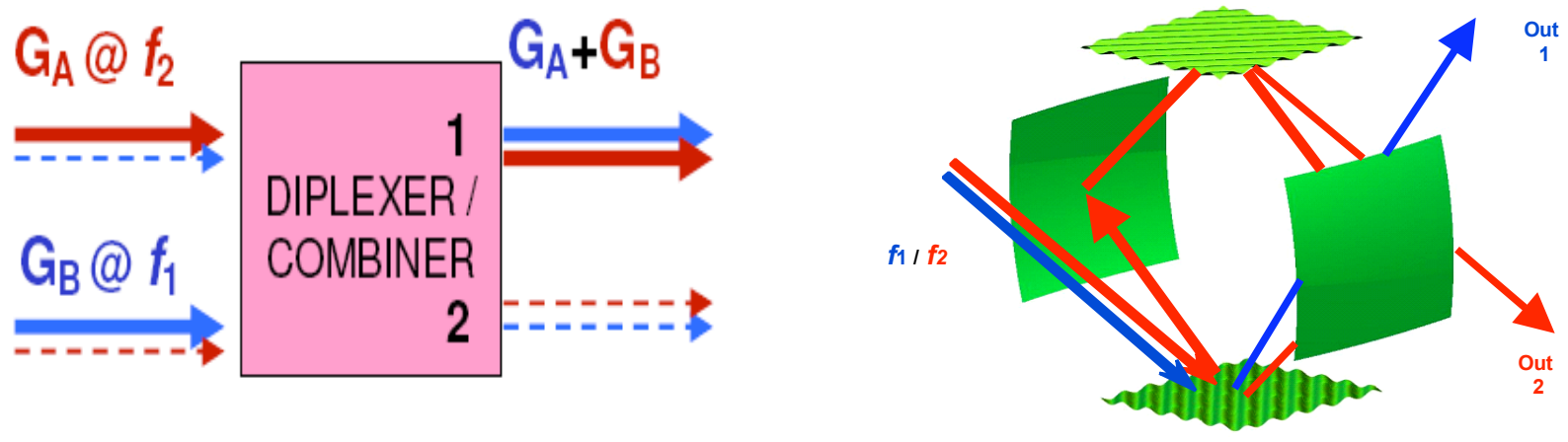
Table 1: Comparison of some basic parameters of the ECRH systems for W7-X, ITER, and JT-60 SA

\begin{tabular}{|c|c|c|c|}
\hline & W7-X & ITER & JT-60 SA \\
\hline Installed Power (MW) & 10 & $24(+3)$ & 9 \\
\hline $\begin{array}{l}\text { Power per gyrotron } \\
\text { (MW) }\end{array}$ & $\begin{array}{l}1 \text { at } 140 \mathrm{GHz} \\
0.4 \text { at } 104 \mathrm{GHz}\end{array}$ & $\begin{array}{l}1 \text { (conventional) } \\
2 \text { (coaxial) }\end{array}$ & 1 \\
\hline Frequency $(\mathrm{GHz})$ & $140 / 104$ & $170(+127)$ & $110 / 140$ \\
\hline $\begin{array}{c}\text { Operation Mode } \\
\text { (standard) }\end{array}$ & $\begin{array}{c}\text { 2nd Harm. }(2.5 \mathrm{~T}) \\
\mathrm{cw}(1800 \mathrm{~s})\end{array}$ & $\begin{array}{c}\text { 1st Harm. }(5.6 \mathrm{~T}) \mathrm{cw} \\
(1000 \mathrm{~s})\end{array}$ & $\begin{array}{l}1^{\text {st }} \operatorname{Harm}(3.1 \mathrm{~T}, 110 \mathrm{GHz}) \\
2^{\text {nd }} \operatorname{Harm}(2.5 \mathrm{~T}, 140 \mathrm{GHz})\end{array}$ \\
\hline Transmission & optical & waveguide & waveguide \\
\hline Launcher & $\begin{array}{c}\text { Front steering/remote steer- } \\
\text { ing }\end{array}$ & Front steering & Front steering \\
\hline \multirow{5}{*}{ Physics demands } & Plasma start-up & Start-up asssist & Start-up assist \\
\hline & \multicolumn{3}{|c|}{ Bulk Heating and Current Drive } \\
\hline & \multicolumn{3}{|c|}{ q-profile shaping } \\
\hline & - & \multicolumn{2}{|c|}{ MHD-control } \\
\hline & Net-current suppression & \multicolumn{2}{|c|}{ Net-current enhancement } \\
\hline
\end{tabular}

Table 2: Representative dimensional parameters R, a, magnetic field B, plasma current I, ECRH-power, heating mix of Ion Cyclotron Resonance Heating (ICRH), Lower Hybrid Heating (LHH), and Neutral Beam Injection (NBI) Heating, respectively, for ITER [12], the next step D-shaped tokamaks EAST, KSTAR [13], SST-1, the next step stellarator W7-X, and the spherical tokamak NHTX.

\begin{tabular}{|c|c|c|c|c|c|c|}
\hline ITER & $\begin{array}{c}\text { R, a } \\
{[\mathbf{m}]}\end{array}$ & $\mathbf{B}[\mathbf{T}], \mathbf{I}[\mathbf{I M A}]$ & $\begin{array}{c}\text { ECRH } \\
{[\mathbf{M W}]}\end{array}$ & $\begin{array}{c}\text { ICRH/LHH/NBI } \\
{[\mathbf{M W}]}\end{array}$ & $\begin{array}{c}\text { Pulse } \\
{[\mathbf{s}]}\end{array}$ & Status \\
\hline $\begin{array}{c}\text { JT-60 SA } \\
\text { (Japan) }\end{array}$ & $3.0,0.95$ & $5.3,15-17$ & $\begin{array}{c}20 \\
(24 \text { inst. })\end{array}$ & $20 / 0 / 33$ & 1000 \\
-3000 & Appr. \\
\hline $\begin{array}{c}\text { EAST } \\
\text { (China) }\end{array}$ & $1.7,0.4$ & $3.5,1$ & $0.5 / 1.5$ & $3 / 3.5 / 8$ & 1000 & Oper. \\
\hline $\begin{array}{c}\text { KSTAR } \\
\text { (Korea) }\end{array}$ & $1.8,0.5$ & $3.5,2.0$ & 5.5 & $8 / 4 / 14$ & 300 & Oper. \\
\hline $\begin{array}{c}\text { SST-1 } \\
\text { (India) }\end{array}$ & $1.1,0.2$ & $3.0,0.22$ & $\begin{array}{c}0.2 \\
(\text { start-up })\end{array}$ & $1 / 1 / 1$ & 1000 & Comm. \\
\hline $\begin{array}{c}\text { W7-X } \\
\text { (EU) }\end{array}$ & $5.5,0.55$ & $3.0,0$ & $\begin{array}{c}9 \\
(10 \text { inst. })\end{array}$ & $4 / 0 / 20$ & 1800 & Constr. \\
\hline $\begin{array}{c}\text { NHTX } \\
\text { (US) }\end{array}$ & $1.0,0.55$ & $2.0,3.5$ & & $50 \mathrm{MW}$ total & 1000 & $\begin{array}{c}\text { Prop. } \\
\text { (D-T) }\end{array}$ \\
\hline
\end{tabular}

